\title{
Conversando nas aulas de Ciências da EJA: prática dialógica por meio das Tecnologias da Informação e Comunicação
}

\section{Conversations in the Science classes of the EJA: Dialogical practice using information and communication technologies}

\author{
${ }^{1}$ Rita Mara Reis Costa ritamara2007@gmail.com \\ ${ }^{2}$ Marcelo Ximenes A. Bizerril
}

\section{RESUMO}

Neste artigo apresentamos uma ação educativa realizada nas aulas de Ciências Naturais do 7o período da Educação de Jovens e Adultos com o objetivo de utilizar práticas dialógicas como argumentação, exposição de ideias e troca de experiências, na forma de instrumentos de construção de conhecimentos científicos relacionados ao funcionamento do organismo humano. As falas e percepções dos estudantes foram extraídas dos momentos de debate, das gravações de áudio e da entrevista semiestruturada aplicada ao final do semestre letivo. Da análise qualitativa dos dados destacam-se o aumento na participação das atividades, a melhora na auto-estima dos estudantes, a partir da valorização dos diversos discursos e uma maior autonomia no processo de ensino-aprendizagem.

Palavras-chave: Educação de Jovens e Adultos. Ensino de ciências na EJA. Abordagem temática. Paulo Freire.

\begin{abstract}
In this article, we present an action education held on Natural Sciences classes for 7th grade for young and adults education which aims to use the dialog practices like argumentation, exposition of ideas and exchange of experiences, as instruments for the construction of scientific knowledge related to the operation of the human body. The students'speeches and perceptions were extracted from debates, the audio recordings and the semi-structured interview conducted at the end of the school semester. From the qualitative analysis of the data, we highlight the increase in participation in the activities, improvement of students' self-esteem, due to the appreciation of a variety of speeches and greater autonomy in the teaching-learning process.
\end{abstract}

Keywords: young and adults education; Science education for adults; thematic approach; Paulo Freire.

1 Mestre em Ensino de Ciências pela Universidade de Brasília e professora da Secretaria de Estado de Educação do Distrito Federal - SEEDF

2 Professor da Faculdade UnB Planaltina, Universidade de Brasília - UnB 


\section{INTRODUÇÃO}

A Lei de Diretrizes e Bases da Educação (LDB) enfatiza que a Educação de Jovens e Adultos (EJA) deve incentivar as potencialidades dos estudantes e promover a sua autonomia, levando-os a serem sujeitos do aprender a aprender, apropriando-se, gradativamente, do mundo do fazer, do conhecer, do agir e do conviver. Na EJA a maioria dos estudantes foi afastada do ambiente formal de ensino por causa de problemas econômicos e sociais, resultado das desigualdades estabelecidas na sociedade. Outra expressiva fração de alunos é resultado de inúmeras e repetidas experiências de fracasso no ensino, como a repetência e a evasão escolar.

Devido a esse contexto, a emancipação dos alunos é um dos princípios norteadores da EJA (BRASIL, 2000), constituindo uma possibilidade de efetivação de um ensino que seja formador de indivíduos críticos e atuantes na sociedade em que estão inseridos. No caso da educação ambiental, por exemplo, Portugal et al. (2013) alertam que não se pode transferir o protagonismo esperado dos adultos para as crianças, consideradas o futuro do planeta, até porque "não se faz educação das crianças sem a educação de adultos" (p.236). Reforçando esta ideia, Gadotti e Romão (2001) afirmam que:

“A EJA se constitui como uma modalidade de ensino que talvez melhor possua condições para contemplar a necessidade de educar indivíduos para a vida com um significado real e concreto, realizando a leitura crítica da realidade mediante os conteúdos propostos” (p. 187).

A educação libertadora que leva à sensibilização do cidadão quanto ao seu papel transformador na sociedade é um dos principais enfoques dos trabalhos realizados por Paulo Freire na educação popular.

Freire (1983) pondera que se há esforço em efetivar uma educação libertadora, os homens não podem ser tratados como objetos da ação educativa. Nesta perspectiva humanista da educação, o estudante deve se apropriar do seu papel central no processo de ensino-aprendizagem, pois, segundo Freire (1983), nessa procura o sujeito se descobre e se conhece.

Paulo Freire (1992), em sua obra Pedagogia da esperança, já demonstrava a sua preocupação em aproximar o conhecimento científico dos problemas do cotidiano dos educandos. Essa inquietação, somada ao papel libertador defendido como função do processo educativo, é facilmente percebida no trecho:

E não se diga que, se sou professor de biologia, não posso me alongar em considerações outras, que devo apenas ensinar biologia, como se o fenômeno vital pudesse ser compreendido fora da trama histórico-social-cultural e política. Como se a vida, pura vida, pudesse ser vivida de maneira igual em todas as dimensões na favela, no cortiço ou numa zona feliz dos “Jardins” de São Paulo. Se sou professor de biologia, obviamente, devo ensinar biologia, mas ao fazê-lo, não posso secioná-la daquela trama (p. 79 )

A concepção de ensino e aprendizagem fundamentada na LDB e nos Parâmetros Curriculares Nacionais - PCN's - para o componente curricular de Ciências Naturais referencia como seu principal objetivo o desenvolvimento de competências essenciais ao exercício da cidadania, "instrumentalizando o estudante para agir no mundo de forma crítica e consciente”.

A proposta de organização dos conteúdos a partir de temas nos currículos educacionais busca dar condições para que essa formação cidadã seja efetiva e não superficial, embasando a formação de atitudes e valores nos docentes e discentes para que se sintam seguros em participar do meio social de forma ativa, crítica e responsável.

O diálogo torna-se a ferramenta dessa interação, valorizando os sujeitos e suas diferentes concepções de mundo. Os meios de comunicação de massa também influenciam sobremaneira no cotidiano e na formação 
dos indivíduos, destarte não deve a escola se privar de discutir a contribuição desses veículos comunicativos na construção dos saberes.

Neste artigo apresentamos uma intervenção realizada nas aulas de Ciências Naturais do 7o período da Educação de Jovens e Adultos com o objetivo de utilizar as práticas dialógicas, como argumentação, exposição de ideias e trocas de experiências, como instrumentos de construção de conhecimentos científicos relacionados ao funcionamento do organismo humano.

\section{BASE TEÓRICA: PRÁTICA DIALÓGICA, COMUNICAÇÃO E ABORDAGEM TEMÁTICA}

Na teoria educacional, política e ética de Paulo Freire (1987) as transformações na sociedade e no indivíduo emergem de uma tomada de consciência da situação cotidiana, problematizando-o e compreendendo-o como um projeto humano. Ainda conforme Freire, a alfabetização não deve ser o ato de repetição de palavras, mas sim o exercício e a capacidade de dizer a sua palavra e que esta tenha sentido próprio como criadora de cultura.

O estudante, na Pedagogia do Oprimido, deixa de ser mero colaborador do processo de aprendizagem e assume o seu papel de agente transformador. Transformação essa que só pode acontecer com o desenvolvimento de uma consciência crítica e responsável a partir da construção da sua história pessoal de libertação. Quando Paulo Freire se refere à libertação, trata-se da possibilidade que a educação deve fornecer ao indivíduo para superar a dominação do homem pelo homem. A autonomia do pensamento defendida nessa pedagogia humanista é a base para que a libertação se efetive.

Santos (2008) argumenta que, segundo a pedagogia humanista e libertadora de Paulo Freire, a autonomia e a capacidade transformadora do indivíduo ocorrem por meio do "diálogo, mediado pelas condições de existência dos temas geradores”. Cabe lembrar que é preciso vivenciar o diálogo e não só se dizer comprometido com ele, como afirma Freire (1983). Para ele, ser dialógico é esforçar-se na transformação constante da sua realidade.

Enfatizando a importância da comunicação no processo educativo de um indivíduo, Lima (2009) afirma que essa capacidade de interação comunicativa possibilita aos agentes do contexto escolar "o envolvimento e o vínculo (...) necessários para o sucesso no processo de educação”.

Para Peruzzo (2002) os estudos sobre comunicação e educação visam as relações e as inter-relações entre essas duas áreas do conhecimento. A autora afirma ainda que no processo de ensino-aprendizagem, mediado pelo processo comunicativo, cabe à educação dos estudantes para a recepção crítica das mensagens emitidas pelos meios massivos, especialmente pela televisão.

Como afirma Silva (2000), os meios de comunicação são concebidos pela indústria cultural e os seus produtos são consumidos pela sociedade e contribuem para a formação intelectual do espectador. Esse impacto é sentido facilmente ao analisar as fontes mais habituais para aquisição da informação, quando se verifica que o livro tem perdido o seu espaço no cotidiano dos jovens, os quais têm "absorvido" informações e até construído valores morais e éticos a partir das programações de televisão, rádio, jornal e internet.

A escola deve ser um espaço para que esses diversos saberes trazidos pelos alunos, oriundos da sua experiência de vida e da sua escuta aos meios de comunicação, consigam interagir e serem refletidos de forma consciente e responsável. Para Lima (2009), ao se abrir ao diálogo o ambiente escolar torna-se um "espaço da convivência densa entre o começo e o fim da criação na produção coletiva de comunicação". 
Com os debates e as construções dialógicas vai se instaurando um processo de intervenção no contexto escolar que, conforme Lima (2009), exige que o professor assuma o seu papel de mediador. O docente deve apresentar "sensibilidade e disponibilidade interior para aguçar a escuta" e "maturidade suficiente para extrair da experiência vivencial" os temas problematizadores do contexto de vida dos estudantes.

O trabalho com os meios de comunicação no ambiente formal de educação deve fomentar o desejo interior no professor e no estudante de manterem-se informados, de aprenderem incessantemente e também de democratizarem a informação e construírem o conhecimento coletivamente, conforme propõe Gaia (2001).

Santos e Mortimer (2000) consideram que a tomada de consciência do indivíduo ocorre por meio do diálogo com as situações propostas pela sua realidade. A proposta de Freire, defendida por esses autores, é que no diálogo devem surgir os conteúdos programáticos a serem trabalhados. Esses conteúdos da educação, por sua vez, devem ser problematizados para possibilitar a conscientização do estudante, mediada pela realidade e objetivando a libertação do indivíduo.

\section{AÇÃO EDUCATIVA REALIZADA}

As primeiras observações relevantes e que forneceram subsídios para as escolhas metodológicas para esta pesquisa ocorreram no primeiro semestre de 2011, quando a primeira autora era mestranda do Programa de Pós-graduação em ensino de Ciências da Universidade de Brasília, e professora de três turmas do $7^{\circ}$ período no turno noturno e teve a oportunidade de observar as relações e as expectativas dos alunos em relação às aulas de ciências. Foi possível observar o desinteresse dos alunos pelos conteúdos de ciências apresentados, pela forma em que eram trabalhados e a falta de envolvimento dos estudantes com as atividades propostas. Diante do exposto, alguns debates foram realizados com o intuito de sondar o motivo do desinteresse pelas aulas e pelas atividades, além de coletar informações que fossem úteis para a elaboração de uma ação educativa neste contexto. Tais debates foram de grande relevância para justificar a ação e os procedimentos metodológicos que seriam adotados no próximo semestre letivo nas aulas de ciências, além de servirem e para delimitar os objetivos desta pesquisa com base nessa realidade pedagógica.

No semestre seguinte, com nova turma de estudantes, o primeiro momento da ação foi uma conversa sobre os aspectos que motivaram os estudantes a retornarem ou permanecerem no ambiente escolar. Habilidades como ouvir e falar foram constantemente desenvolvidas a partir da prática e do respeito aos múltiplos discursos presentes no ambiente escolar.

As conversas foram enriquecidas a partir da leitura de textos, músicas ou algum produto da mídia que tratava sobre o que é a escola e o seu papel. Ao final desses diálogos os estudantes foram convidados a gravar algumas de suas falas de maneira informal em um gravador de áudio, como instrumento para socializar essa experiência com outra turma também envolvida na ação, em um processo inspirado pelo método do Cassete Fórum, proposto por Kaplún (1984).

No segundo momento os estudantes foram convidados a ouvirem produtos da mídia como reportagens, áudios de programas de rádio, gravações da internet que versavam sobre a importância da educação. As discussões eram orientadas para buscar quem seriam os responsáveis pelo sucesso no processo de ensino-aprendizagem. Os estudantes eram encorajados a sentirem-se participantes ativos deste processo e a posicionarem-se criticamente frente alguns problemas enfrentados no seu contexto escolar.

No terceiro momento os estudantes foram apresentados às possibilidades de temas a serem trabalhados ao longo do semestre letivo na disciplina de ciências, conforme o quadro 1. Para listar os temas a professora levou em conta a sua relevância frente aos problemas e as demandas apresentadas pelos seus estudantes da EJA, da 
turma atual e do semestre anterior. Cabe a ressalva de que apesar dos temas terem partido da vivência significativa dos educandos, evitamos classificar essa ação como um trabalho com temas geradores, uma vez que não foram aplicadas as etapas metodológicas da investigação temática (Freire, 1987; Delizoicov et al., 2009), mas, na verdade, buscou-se enfocar temas correlacionados ao conteúdo central previsto no currículo da Educação Básica, que era o funcionamento do organismo humano. Contudo, consideramos que foi realizada uma abordagem tipo temática dada a perspectiva crítica gerada a partir da possibilidade que as discussões nas aulas tiveram de problematizar a realidade e instigar o estudante a buscar o conhecimento e propor soluções, intervindo no mundo em alguma proporção. De modo similar, o trabalho de Strieder (2012) traz interessante discussão a respeito das possibilidades de articulação da perspectiva freireana com o enfoque CTS (Ciência - Tecnologia - Sociedade), sugerindo alternativas à investigação temática no processo de seleção dos temas.

Para a realização dos trabalhos, algumas práticas foram constantes como a apresentação de produtos da mídia (programas de rádio, televisão, vídeos ou imagens da internet) que tratavam do tema como mecanismo motivador para as discussões e as construções de conhecimento, além de propiciar reflexões sobre o papel dos meios de comunicação no nosso cotidiano. Gravações de áudio foram utilizadas para motivar a reflexão e a troca de experiências entre as turmas que estavam participando da ação.

Quadro 1. Temas propostos para a disciplina de ciências.

\begin{tabular}{|c|c|}
\hline Tema & Aspecto do corpo humano destacado \\
\hline -Alimentação Saudável & -Sistema Digestório \\
& -Sistema Sensorial \\
\hline -Automedicação & -Sistema Respiratório \\
-Drogas & - Sistema Excretor \\
& - Sistema Nervoso \\
-Doenças Sexualmente Transmissíveis & -Sistema Cardiovascular \\
(DST) e Planejamento Familiar & -Sistema Reprodutor \\
& -Sistema Nervoso \\
\hline
\end{tabular}

Para orientar as discussões, a professora valeu-se de algumas perguntas que motivavam os estudantes a pensar sobre o tema apresentado, relacionando o conteúdo aos problemas cotidianos. Posteriormente, os estudantes foram convidados a realizar uma pesquisa aprofundando os seus conhecimentos sobre o tema, para que os debates pudessem continuar. Após a realização da pesquisa os estudantes expuseram os resultados para a turma na forma de seminário, debates sobre o tema ou ainda, em registros pessoais escritos.

\section{PROCEDIMENTOS DE ANÁLISE}

A pesquisa seguiu a metodologia qualitativa para a produção e análise dos dados, optando pelo método da pesquisa-ação, utilizando como instrumentos investigativos as observações, análise de relatos individuais (redações) construídas pelos participantes e entrevistas semiestruturadas.

Tozoni-Reis (2005) propõe que a pesquisa em educação prime pela essência qualitativa porque visa explorar um contexto dinâmico, diverso e específico. Dessa forma, a pesquisa qualitativa foi adequada para este estudo, pois havia um contato direto e prolongado da pesquisadora com o contexto das turmas investigadas, no papel de professora regente. Outra característica que justifica a metodologia qualitativa para este trabalho é que os dados construídos têm caráter descritivo, levando em conta a percepção do investigador sobre as falas e as situações observadas, como propõe Lüdke e André (2012). Os instrumentos que foram escolhidos para a cons- 
trução dos dados possibilitaram elucidar o dinamismo interno das aulas de ciências e visualizar as perspectivas dos participantes sobre a sua atuação nas atividades propostas.

Segundo André (2001), a adoção da pesquisa-ação pelo professor é uma metodologia emancipatória por possibilitar ao docente uma reflexão consciente de sua prática pedagógica. A escolha metodológica da pesquisa-ação traz a possibilidade de intervenção no contexto da sala de aula, abarcando o objetivo de melhorar-se e desenvolver-se pessoal e profissionalmente. A caracterização deste trabalho na metodologia de pesquisa-ação se dá principalmente pela: apresentação junto aos estudantes dos problemas enfrentados nas aulas de ciências naturais; discussão sobre os objetivos da pesquisa e apresentação da proposta de trabalho sobre a autonomia do estudante e as aulas temáticas de ciências naturais inspiradas nas ideias de Paulo Freire; aceitação de modificações nos temas ou na sua ordem de apresentação por parte dos participantes e a avaliação dos resultados da pesquisa de forma coletiva. Esses aspectos coadunam com o que Thiollent (2007) apresenta sobre a fundamentação da pesquisa-ação no diálogo entre o pesquisador e os demais participantes da investigação, tendo como uma das competências a ser atingida no processo de pesquisa, a argumentação e a valorização do saber espontâneo do participante.

As observações ocorreram quando os estudantes estavam reunidos ouvindo, assistindo ou lendo os produtos dos meios de comunicação ou realizando as práticas comunicativas, discutindo, pesquisando, apresentando suas pesquisas, gravando comentários ou elaborando textos. A intenção que permeou esta observação foi de construir dados sobre a dinâmica e o comportamento interno dos grupos de estudantes. A observação participante e as anotações dos acontecimentos mais significativos e relevantes no diário de campo foram ferramentas importantes nas atividades dialógicas. As descrições realizadas no diário de campo foram assíncronas na maioria das aulas, ocorrendo no momento de mudança de turma ou no intervalo, na sala dos professores. Em algumas aulas foram solicitadas relatos escritos dos estudantes a respeito do tema exposto com dois objetivos primordiais, a continuação do processo argumentativo que estava acontecendo na aula de ciências e também como instrumento de avaliação escolar.

O momento da avaliação coletiva da pesquisa teve papel fundamental para a retomada aos objetivos traçados e apresentados no início da sua aplicação para ouvir os depoimentos e as declarações de todos participantes. As entrevistas semiestruturadas coletivas (na forma de debate, em cada turma) e as individuais (realizadas com os alunos convidados ou interessados em participar) visaram avaliar a ação nas aulas de ciências, como retomar aos objetivos da pesquisa e analisar o seu alcance. As questões propostas aos estudantes visaram levantar dados para evidenciar a importância desta ação na realidade da disciplina de ciências naturais, verificar a relevância dos temas geradores desenvolvidos nas aulas e construir dados sobre a possibilidade de aprender ciências por meio das práticas dialógicas e dos meios de comunicação.

\section{RESULTADOS E DISCUSSÃO}

Os resultados foram agrupados conforme as principais etapas do projeto desenvolvido que foram a valorização da trajetória pessoal e a aplicação de um programa de ensino baseado no uso de temas e das Tecnologias da Informação e Comunicação. Os extratos das falas revelaram a importância das ações desenvolvidas para a socialização, o desenvolvimento da autoestima, e, sobretudo, na promoção da participação coletiva na construção do conhecimento.

\section{1 Valorização da Trajetória Pessoal}

Nos primeiros debates realizados nas salas de aula da 7a etapa da EJA sobre a importância da escola e sobre o motivo que os havia trazido para aquele ambiente foi possível identificar em alguns estudantes um sen- 
timento de culpa e fracasso em relação a não terem frequentado o ambiente escolar na idade regular, conforme as falas:

“Tive que trabalhar muito cedo e não tive como ir pra escola não”. (aluno F., 7P)

"E tô aqui professora porque quando estava na idade certa não achava graça na escola, agora tenho que correr atrás do tempo perdido, porque já tá passando da hora, né?” (aluno K., 7P)

Diversos são os motivos que trazem o jovem e o adulto a retornarem ao ambiente escolar na modalidade da EJA, com destaque para o papel do estímulo da família:

"O que me trouxe à escola foi em primeiro lugar, foi quando os meus filhos me pediram a oportunidade de fazer algo para ajudar eles nas matérias e eu não conseguia. Aí isso naquele momento me deixou triste, me deixou totalmente sem graça e através disso eu vim à escola e hoje eu estou com dois anos e meio estudando e estou chegando a sétima séria, e peço a Deus que eu chegue até o fim dessa matéria”. (aluna S., 7P)

Como afirmam Pompeu e Zimmermann (2009), com a EJA, a educação brasileira tem trazido para os bancos das escolas as minorias excluídas e desfavorecidas, uma vez que tem se buscado construir no país a alfabetização social a partir da prática da cidadania de forma crítica e consciente. A educação desses indivíduos deve preconizar o diálogo como forma de efetividade e exercício de sua liberdade e transformação (FREIRE, 1987).

A valorização da história de cada um mostrou-se importante por ajudar os estudantes a elaborarem e fortalecerem suas razões pessoais para voltarem à escola:

"Eu não estou aqui estudando pra provar pra ninguém que eu consigo, mas sim pra mim mesmo que eu sou capaz, que eu vou buscar e eu vou conseguir.” (aluna F, 7Q).

Por outro lado, alguns ressaltaram sua incompreensão com a nova forma de iniciar as aulas de ciências como, por exemplo:

“Este é o conteúdo de ciências da $7^{a}$ série? O que interessa é que eu to aqui, ora!” (aluno T, 7R).

“Qui professora, larga dessas conversas e dá logo o seu conteúdo aí!” (aluno J, 7R).

“Quer dizer que vai ser tudo conversa, é isso?” (aluna F, 7Q).

A estranheza sentida por alguns educandos a respeito das discussões propostas é possivelmente embasada na distância estabelecida na relação professor-aluno. Oliveira (2001) estabelece uma configuração básica para o "modelo escolar tradicional", que constitui um estereótipo bastante generalizado na sociedade. Afirma esta autora que na escola há um professor que ensina e estabelece as normas aos estudantes que devem, por sua vez, aprender e obedecer. Ao perguntar sobre a sua vida e sentar-se junto com os educandos, parte desse estereótipo é ferido, o que gera incômodo em alguns estudantes mais familiarizados com o processo escolar tradicional e menos acostumados a transformações e mudanças neste ambiente.

Conhecer e interessar-se pela história de vida do estudante na EJA torna-se imprescindível para a construção positiva de uma relação professor-aluno. Como salienta Pinheiro (2004), o conhecimento das necessidades educacionais dos educandos possibilita o êxito nas intervenções pedagógicas e nas escolhas de metodologias que promovam o seu desenvolvimento. 
Após as discussões das trajetórias pessoais, enfatizou-se a história de Paulo Freire na educação de adultos, onde estes eram alfabetizados levando em conta a sua experiência de vida e abrindo nas aulas a possibilidade de discutir problemas do dia-a-dia e propor soluções coletivamente. Foi apresentada a concepção de educação bancária, fazendo com que muitos estudantes comentassem que a maioria das suas aulas seguia este padrão: o professor sabe tudo e o educando não sabe nada; cada um no seu papel, um só ensina e o outro só aprende. Após a proposição do método de aulas temáticas algumas perguntas foram respondidas, outras foram debatidas, direcionando o trabalho que seria realizado coletivamente com as turmas nas próximas etapas.

\section{2 A organização por temas e o uso das Tecnologias da Informação e Comunicação}

A proposta desenvolvida por este trabalho era a participação coletiva na construção do conhecimento a partir da valorização do saber trazido pelos educandos para os momentos de debate, e a estimulação do estudante para a pesquisa e a busca do conhecimento após interagir com um produto oriundo dos meios de comunicação.

A vivência dos estudantes, o conhecimento adquirido a partir da sua experiência de vida e o grande contato que tinham com os meios de comunicação de massa fez com que os estudantes apresentassem bastante interesse e compreensão a respeito dos temas estudados.

A respeito da alimentação saudável, automedicação, drogas, doenças sexualmente transmissíveis e do planejamento familiar, temas motivadores das aulas, o conhecimento trazido pelos estudantes apresentavam muita coerência com o conhecimento científico. Além disso, após o debate dos educandos, apresentando seus conhecimentos e suas experiências sobre os temas, era solicitado um aprofundamento sistematizado em cada temática, desencadeando uma pesquisa, num processo similar ao da teorização, proposto por Berbel (1995) na metodologia de problematização a partir do arco de Maguerez.

As pesquisas eram direcionadas aos aspectos desconhecidos do tema, como por exemplo, o funcionamento da digestão humana, doenças relacionadas ao mau funcionamento de determinado sistema orgânico, ação de algumas drogas, relação entre as doenças sexualmente transmissíveis e o planejamento familiar, entre outras. A busca pelo conhecimento científico nas pesquisas tinha por objetivo primordial instrumentalizar o estudante para um futuro debate e apresentação de posicionamentos, para que no ambiente de diálogo da sala de aula fosse construído e socializado o conhecimento científico.

A pesquisa escolar teve um papel importante no encontro entre o conhecimento científico e o entendimento baseado na vivência dos estudantes, gerando por vezes novas escolhas e formulação de conceitos. Nesse sentido, o aluno J da turma 7P, no primeiro debate sobre drogas afirmou que: "O drogado não tem jeito professora, a droga acaba com a pessoa. Agora o cigarro, professora, é diferente, paga imposto, é tudo legal. Fumar cigarro pode, ninguém vai ser preso." E quando perguntado sobre a saúde de quem fuma, argumentou: "Tudo faz mal, comer pode fazer mal, cigarro é igual.”

Depois dos debates e de realizar uma pesquisa sobre o cigarro, a sua composição química e os riscos para a saúde, em apresentação para a turma, reviu sua posição: "É gente, cigarro é droga também. Eu não sabia que tinha tanto veneno lá não. Só estudando para saber mesmo, viu?”

O trabalho com aulas temáticas visa aproximar o componente curricular de Ciências Naturais da realidade vivenciada pelo estudante. A formação de cidadãos conscientes e capazes de se posicionarem de forma autônoma e crítica frente aos temas de ciências naturais é um dos objetivos desse tipo de abordagem. O processo educacional deve ser direcionado para o diálogo, a argumentação, a exposição de ideias e a reflexão, sendo o educando considerado protagonista do seu desenvolvimento e sua formação integral. Ao posicionar-se ativamente no seu processo de ensino-aprendizagem o educando capacita-se para refletir sobre as questões sociais que envolvam 
ciência, tecnologia e ambiente de forma a desenvolver um senso crítico, valores e responsabilidades preponderantes para a sua atuação transformadora na sociedade (MUNDIM, 2009).

Ainda que parte dos estudantes tenha demonstrado domínio do conteúdo científico após a realização das pesquisas, outros alunos ainda resistiam à nova metodologia e mostravam pesquisas superficiais ou cópias desconexas de livros ou sites da internet. A profundidade da pesquisa era sentida na capacidade de argumentação dos alunos quando eram perguntados pelos colegas ou professora sobre algum aspecto discutido.

No que tange ao uso das tecnologias de informação e comunicação no dia-a-dia em sala de aula, a experiência com uso das gravações de relatos pessoais entre as turmas, inspiradas no método Cassete-Fórum, foi bem sucedida em promover a habilidade de ouvir atentamente e posicionar-se frente às falas dos colegas. Kaplún (1984) considera que a comunicação deve incentivar e promover reflexões, tomada de consciência crítica da realidade e estimular a liberdade e a solidariedade entre os agentes. A convivência social é o pilar das práticas educomunicativas, uma vez que segundo Soares (2010), só a partir dessa convivência é que os indivíduos são capazes de expressar suas necessidades e enxergar as possibilidades de mudanças no seu contexto.

Durante as aulas temáticas os estudantes por várias vezes foram indagados a respeito do papel da mídia na transmissão de informações úteis sobre o funcionamento do corpo humano e na prevenção de doenças. Algumas falas ilustram a percepção da importância que a mídia pode exercer nesses aspectos:

“Tem uns programas de televisão hoje professora que trata sobre a saúde na alimentação, mas passa num horário que nem todo mundo pode pegar.” (aluna A, 7P)

"A televisão tem mais é que falar sobre as drogas e sobre os perigos de usá-las. Porque todo mundo tem televisão hoje em dia e assiste é muito.” (aluno K, 7P)

"Porque ciências é uma coisa assim que a gente vive no dia-a-dia... Com certeza dá pra usar jornal, vídeo e a gente aprende cada vez mais” (aluna F da turma 7Q)

Diversos programas de televisão, incluindo novelas, foram citados pelos estudantes na tentativa de fundamentar que os meios de comunicação de massa têm se comprometido com a transmissão de conhecimentos sobre o funcionamento do corpo humano. Aparentemente, prevaleceu nos debates a visão ingênua sobre o papel educativo da mídia, sendo praticamente ausente uma leitura crítica dos meios de comunicação e sobre a atuação da televisão na formação dos indivíduos. Essa visão ingênua predominante pode ser justificada pelos recortes dos programas utilizados nessa ação educativa. Os trechos utilizados e as discussões, em sua maioria, focaram mais os conteúdos estritamente científicos e possibilitaram poucas reflexões sobre a formação de opinião e a influência da mídia na imposição de valores.

\section{3 Desenvolvimento da auto-estima e a construção coletiva do conhecimento}

Foram observadas mudanças no comportamento inicial de alguns educandos, que inicialmente se apresentavam agitados e inquietos, e com o desenvolvimento das aulas tornaram-se focados e participativos nas atividades. Foi notável a diminuição de conversas paralelas durante as aulas e o desrespeito às falas dos colegas também sofreu grande baixa ao final do semestre. A atenção e o saber ouvir o outro foram habilidades desenvolvidas por vários estudantes ao longo da ação educativa.

Outros estudantes conseguiram superar as barreiras da timidez e vergonha, conseguindo, ao longo do semestre, gradualmente participar dos debates e apresentarem a sua experiência de vida sobre o tema apresentado. 
Um fato perceptível ao longo da ação pedagógica foi o aumento no número de participações nos debates. Esse aspecto é um reflexo da relação entre os temas de ciências com o cotidiano dos estudantes, e do aumento das possibilidades de expressão, previstos nas metodologias defendidas por Paulo Freire e Mário Kaplún. Segundo Kaplún (1984), a democratização da comunicação deve iniciar ou passar por um diálogo participativo de um pequeno grupo de indivíduos, valorizando os diversos discursos, embasados nas experiências pessoais, mas visando a coletividade. Como visto, outras dimensões desenvolvidas através do método do Cassete Fórum, foram também reconhecidas nesse estudo, como o sentimento de pertencimento a um grupo, aumento da auto-estima do indivíduo, valorização do que é próprio e a aquisição de uma segurança na sua própria capacidade.

Nos últimos debates realizados no semestre foi possível perceber que os alunos demonstravam empenho, segurança e liberdade ao expressarem as suas opiniões e comentários. A maioria dos estudantes apresentou capacidade de fazer crítica e de analisar o conhecimento apresentado nas conversas em sala de aula, assim como clareza e capacidade de argumentação com relação aos temas trabalhados.

Os registros escritos ilustram a mudança de postura de alguns alunos que antes se apresentavam indiferentes e desinteressados no início da aplicação da proposta de ação educativa. Esses alunos, em momentos diferentes do programa, apresentaram interesse e envolvimento com as atividades propostas.

Mudanças significativas foram sentidas quanto ao respeito à fala dos colegas nos debates, compromisso na realização das pesquisas, além da habilidade argumentativa que foi desenvolvida em alguns alunos. Não era raro um estudante expor para a turma que não havia realizado a pesquisa solicitada por falta de tempo ou outro motivo, mas que iria pesquisar e traria as suas impressões em aulas posteriores, e realmente cumprir o seu compromisso. Tais mudanças despertaram nos alunos uma necessidade de refletir sobre as aulas ministradas em outras disciplinas, extrapolando as aulas de ciências naturais. No entanto, o resultado mais marcante dessa ação foi a mudança na postura dos estudantes que inicialmente encontravam-se passivos frente ao processo de aprendizagem em ciências e que, com o decorrer do processo, tornaram-se sujeitos da sua própria história e sentiram-se responsáveis pela sua aprendizagem, como demonstram as falas a seguir, quando questionados sobre o que acharam dos temas trabalhados nas aulas de ciências:

"Eu aprendi muita coisa, coisa que eu não sabia eu descobri nas aulas de ciências e nas pesquisas deste semestre.” (aluno R da 7P).

"Eu aproveitei muito, sabe eu conheci muito, tinha muita coisa assim, que eu não tinha nem descoberto antes, então um passinho a mais, um empurrãozinho foi importante e muito bom”. (aluna F da 7Q).

As práticas dialógicas possibilitaram uma nova dinâmica nas aulas de ciências naturais e o compromisso do estudante com a disciplina era movido pelo seu interesse em compartilhar suas experiências. As respostas fornecidas nas conversas em sala de aula e na entrevista ressaltam a importância do desenvolvimento de momentos dialógicos como estratégias no processo de ensino-aprendizagem em ciências:

"E achei bem diferente porque a gente não pegou tanto no lápis e caneta como nas outras aulas passadas, nos outros semestres. A gente fez mais debates, discutiu e foi bem divertido até, melhor pra gente aprender." (aluno R da turma 7P).

\section{CONSIDERAÇÕES FINAIS}

Nessa modalidade de educação básica, a necessidade de propostas e estratégias criativas devem ser constantes, visando alcançar as diversas motivações e realidades vivenciadas pelos estudantes. O diálogo, como 
instrumento que possibilita a troca de experiências e o enriquecimento do processo educativo, deve permear qualquer programa destinado a esse público.

Vislumbrar um processo educativo onde a escola tenha como papel principal a transmissão de conhecimentos prontos e acabados, além de desinteressante é ineficiente por ser totalmente desvinculado da realidade. O conhecimento produzido no ambiente escolar promove a motivação no estudante e também no professor, que vê os seus objetivos sendo alcançados na participação e interesse dos educandos.

A liberdade e a valorização das falas devem ser a base para a reflexão e o diálogo, assim como a proposta de ação presente neste trabalho pode ser vista como uma das muitas estratégias para o desenvolvimento das aulas de ciências naturais na EJA. Seja qual for a estratégia adotada pelo professor para trabalho na EJA é relevante que leve em consideração a diversidade de discursos que se apresentam na sua sala de aula. Os saberes que o estudante apresenta, oriundos da sua experiência de vida, têm que ser levados em consideração como ponto de partida para as aulas.

Ao valorizar o contexto e o conhecimento trazidos pelos estudantes faz-se necessária a utilização de problemas e proposições que lhe sejam mais concretas, justificando, dessa forma, a adoção de uma abordagem temática na perspectiva de aproximar os estudantes dos conhecimentos científicos a partir da realidade vivenciada.

As proposições discutidas nesse artigo certamente devem ser consideradas aplicáveis para as demais modalidades de ensino de ciências, especialmente no ensino básico. Contudo, a EJA, por tratar-se de uma modalidade de ensino tão peculiar, é um ambiente adequado para ações pedagógicas que possibilitem aos estudantes reconhecerem-se como protagonistas do seu processo de ensino-aprendizagem. Assumindo o papel central no processo educativo, o estudante reconhece-se como autor da sua própria história, autônomo na busca do conhecimento e rumo ao processo libertador, defendido por Freire (1987). 


\section{REFERÊNCIAS BIBLIOGRÁFICAS}

ANDRÉ, M. (org.) O papel da pesquisa na formação e na prática dos professores. (série Prática Pedagógica). Campinas, SP: Papirus, 2001.

BERBEL, N.A.N. Metodologia da problematização: uma alternativa metodológica apropriada para o ensino superior. Semina, Londrina, v.16, n.2, p:9-19, 1995.

BRASIL. CNE - Conselho Nacional de Educação. Câmara de Educação. Parecer nº 11/2000 e Resolução no 01/2000: Diretrizes Curriculares Nacionais para a Educação de Jovens e Adultos. Brasília, 2000.

BRASIL. Lei no 9.394, de 20/12/96. Lei de Diretrizes e Bases da Educação Nacional.

DELIZOICOV,D.;ANGOTTI,J.A.; PERNAMBUCO,M.M. Ensino de Ciências: Fundamentos e Métodos. São Paulo, Cortez: 2009.

FREIRE, P. Extensão ou comunicação? Rio de Janeiro: Paz e Terra, 1983.

FREIRE, P. Pedagogia do Oprimido. Rio de Janeiro: Paz e Terra. 1987.

FREIRE, P. Pedagogia da Esperança - um reencontro com a Pedagogia do Oprimido. Rio de Janeiro: Paz e Terra, 1992.

GAIA, R. V. Educomunicação \& mídias. Maceió: EDUFAL, 2001.

GADOTTI, M.; ROMÃO, J. E. Educação de Jovens e adultos: teoria, prática e proposta. São Paulo: Cortez, Instituto Paulo Freire, 2001.

KÁPLUN, M. Comunicación entre grupos. el método del Cassete-Foro. Ottawa, International Development Research Centre, Canada, 1984.

LIMA, G. L. Educação pelos meios de comunicação ou Produção Coletiva de Educação na perspectiva da Educomunicação. Disponível em: <http://portalgens.com.br/portal/educomunicacao $>$.São Paulo: Instituto de GENS de Educação e Cultura, 2009. Último acesso em: dez de 2011.

LÜDKE, M.; ANDRÉ, M.E.D.A. Pesquisa em educação: abordagens qualitativas. São Paulo: EPU, 2012.

MUNDIM, J. V. Avaliação da Abordagem de um Tema CTS em Aulas de Ciências das Séries Finais do Ensino Fundamental: Análise de uma Intervenção Pedagógica. Dissertação de Mestrado, Faculdade de Educação, Universidade de Brasília. 2009.

PERUZZO, C. M. K. Comunicação comunitária e educação para a cidadania. PCLA, v.4., n.1, 2002. Disponível em http://www2.metodista.br/unesco/PCLA/revista13/artigos\%2013-3.htm. último acesso em jan 2014.

POMPEU, S.F.C.; ZIMMERMANN, E. Concepções sobre ciências e ensino de ciências de alunos da EJA. In: Anais do VII Encontro Nacional de Pesquisa em Educação em Ciências. 2009.

PORTUGAL, S.; SORRENTINO, M.; VIEZZER, M. Educação ambiental na formação de jovens e adultos. In: SORRENTINO, M. (org.). Educação ambiental e políticas públicas: conceitos, fundamentos e vivências. 1ed. Curitiba: Appris. 2013. p. 225-243.

SANTOS,W.L.P. Educação Científica Humanística em uma perspectiva Freireana: resgatando a função do Ensino de CTS. Alexandria Revista de Educação em Ciência e Tecnologia, v. 1, n.1, p. 109-131, 2008. 
SANTOS,W.L.P.; MORTIMER, E.F. Uma análise de pressupostos teóricos da abordagem C-T-S (ciênciatecnologia-sociedade) no contexto da educação brasileira. Ensaio: pesquisa em educação em ciências, v. 2, n.2, 133-162, 2000.

SILVA, Y. J. Meios de comunicação e educação - o rádio, um poderoso aliado. In: Outras linguagens na escola: publicidade, cinema e TV, rádio, jogos, informática. São Paulo: Cortez, 2000.

SOARES, D. Educomunicação: dimensão social e política. Disponível em: http://portalgens.com.br/portal/ images/stories/educomunicacao/Educomunicao_dimenso_social_e_poltica/Educomunicao_dimenso_social_e_ poltica.pdf. 2010. Último acesso em: jan. 2014.

STRIEDER, R.B. Abordagens CTS na educação científica no Brasil: sentidos e perspectivas. Tese de Doutorado, Universidade de São Paulo, São Paulo, 2012.

THIOLLENT, M. Metodologia da Pesquisa-ação. 15.ed. São Paulo: Cortez, 2007.

TOZONI-REIS, M.F.C. Pesquisa-ação: Compartilhando saberes, pesquisa e ação educativa ambiental. In: Encontros e Caminhos: formação de educadoras(es) ambientais e coletivos educadores. Ministério do Meio Ambiente. Brasília, p. 267-276, 2005. 